Vol 12, Issue 1, 2019

\title{
OPTIMIZATION AND SOLUBILIZATION STUDY OF NANOEMULSION BUDESONIDE AND CONSTRUCTING PSEUDOTERNARY PHASE DIAGRAM
}

\author{
RAMAN KUMAR PUPPALA*, VIJAYA LAKSHMI A
}

Department of Pharmaceutical Technology, Vels Institute of Science, Technology and Advanced Studies (VISTAS), Chennai, Tamil Nadu, India. Email: ram4599@gmail.com

Received: 24 July 2018, Revised and Accepted: 18 September 2018

\section{ABSTRACT}

Objective: The aim of the present study was to formulate and optimize budesonide nanoemulsions for targeting inflammation.

Methods: Budesonide is only found in individuals that have used or taken this drug. It is a glucocorticoid used in the management of asthma, the treatment of various skin disorders, and allergic rhinitis. The exact mechanism of the action of budesonide in the treatment of Crohn's disease is not fully understood. However, being a glucocorticosteroid, budesonide has a high local anti-inflammatory effect. The formulation was optimized for different components and the solubility study for the oil in surfactant and cosurfactant mix ratio was optimized using ternary phase diagram.

Results: The surfactant mix ratio was optimized as 1:3 where the maximum concentration of the oil has solubilized and the nanoemulsion area was increased.

Conclusion: Budesonide nanoemulsion for targeting inflammation and the pseudoternary phase diagram for the solubility studies and the components of different phases were optimized and achieved through this study.

Keywords: Nanoemulsion, Budesonide, Pseudoternary phase diagram solubility, Anti-inflammatory effect.

(C) 2019 The Authors. Published by Innovare Academic Sciences Pvt Ltd. This is an open access article under the CC BY license (http://creativecommons. org/licenses/by/4. 0/) DOI: http://dx.doi.org/10.22159/ajpcr.2019.v12i1.28686

\section{INTRODUCTION}

Nanoemulsions [1] are high solubilizing and drug protection features have the potential to deliver proteins as well as other new (or traditional) active drug compounds. Although authors have suggested using nanoemulsion formulations for inflammation [2-7]. Budesonide (16,17-butylidenebis(oxy)-11,21-dihydroxypregna-1,4-

diene-3,20-dione) is a synthetic glucocorticoid steroid used in the treatment of asthma and an inflammatory bowel disease [9]. Molecular weight of budesonide is 430.5, log $p$ values are 3.2, biopharmaceutical classification system Class II and practically insoluble in water $(28 \mu \mathrm{g} / \mathrm{mL})$ [10]. It is a potent non-halogenated corticosteroid and has a relative glucocorticoid receptor affinity of 935 compared with 100 for dexamethasone and a 200-fold higher glucocorticoid receptor affinity and a 1000-fold higher topical anti-inflammatory potency than cortisol [11]. Budesonide is completely absorbed from the gastrointestinal tract; however, its bioavailability is around $10 \%$ due to hepatic first-pass effect [12]. Due to degradation of budesonide in the liver easily, an alternative way should be developed to avoid the first-pass effect, thereby the cellular uptake in the site of action is enhanced [13]. The droplet size of the nanoemulsion typically falls in the range of $20-30 \mathrm{~nm}$ and shows a narrow sized distribution. It consists of two phases, one is aqueous phase and the other is oil phase. The excipient to be used is selected using preformulation studies. The optimization of the oil, surfactant, and water in the formulation is done by solubility study. The optimum concentration of the oil that could be solubilized with the surfactant mix (Smix) is optimized using pseudo ternary phase diagram.

\section{METHODS}

Budesonide (Hetero Lab Pvt., Ltd., gift sample), polyoxyl 35, castor oil (SD Fine Chem, Ltd., Mumbai), Tween 80 (SD Fine Chem Ltd., Mumbai), polyethylene glycol (PEG) 400 (SD Fine Chem, Ltd., Mumbai), ethanol (SD Fine Chem, Ltd., Mumbai), Probe Sonicator, Bath Sonicator,
Magnetic Stirrer, and high-performance liquid chromatography (HPLC) were used.

\section{Preformulation studies}

The preformulation study was mainly done to determine the physical, chemical, and various pharmaceutical properties [14] of all the components (including drug) alone and also when combined together in the formulation. The main objective of the preformulation study was to produce a stable product with specified drug content (often 90-95\%).

\section{Solubility studies}

Optimization of oil

The optimization of oil [14] can be done by adding excess of drug in $2 \mathrm{ml}$ of fixed oils such as polyoxyl 35 oil, castor oil, super refined olive oil, medium chain triglyceride (palm kernel oil), soya bean oil, Labrafac propylene glycol (PG), triacetin, and isopropyl myristate separately in a $5 \mathrm{ml}$ capacity three stopper vials for 1 week-1 month and mixed using vortex mixer. The samples were then centrifuged at $3000 \mathrm{rpm}$ for $15 \mathrm{~min}$. The supernatant was taken and then filtered. The concentration of budesonide in these oils was determined using HPLC.

\section{Optimization of surfactant}

The surfactant selection [16] was done by adding $4 \mathrm{ml}$ of selected oil to $2.5 \mathrm{ml}$ of surfactant solution (15\% V/V surfactant in water) and mixed using vortex mixer. The mixing was performed until a clear solution obtained. In the similar way, cosurfactant was also optimized.

\section{Preparation of pseudoternary phase diagram}

On the basis of optimization [17] studies, polyoxyl 35 was selected oil phase and tween 80 and ethanol were selected as surfactant and cosurfactant, respectively. Distilled water was used as aqueous phase. The surfactant and cosurfactant were mixed at different mass ratios 
Table 1: Composition of the solubility of budesonide in various oils, surfactant, and cosurfactant at $70^{\circ} \mathrm{C}(\mathrm{mean} \pm \mathrm{SD}, \mathrm{n}=3$ )

\begin{tabular}{|c|c|c|c|}
\hline Oil & Solubility (mg/ml) & Surfactant & Solubility $(\mathrm{mg} / \mathrm{ml})$ \\
\hline Castor oil & $52 \pm 0.1$ & Tween 80 & $29 \pm 1.3$ \\
\hline Polyoxyl 35 & $53 \pm 0.1$ & Ethanol & $30 \pm 1.3$ \\
\hline Super refined olive oil & $7 \pm 0.1$ & $\mathrm{PG}$ & $0.6 \pm 1.3$ \\
\hline Soya bean oil & $2 \pm 0.05$ & Tween 20 & $15 \pm 0.5$ \\
\hline MCT (palm kernel oil) & $8 \pm 0.4$ & Tween 80 & $5 \pm 0.02$ \\
\hline Labrafac PG & $1 \pm 0.04$ & Transcutol & $39 \pm 0.2$ \\
\hline Triacetin & $3 \pm 0.6$ & PEG 200 & $35 \pm 0.5$ \\
\hline
\end{tabular}

PEG: Polyethylene glycol, MCT: Medium chain triglyceride, PG: Propylene glycol, SD: Standard deviation

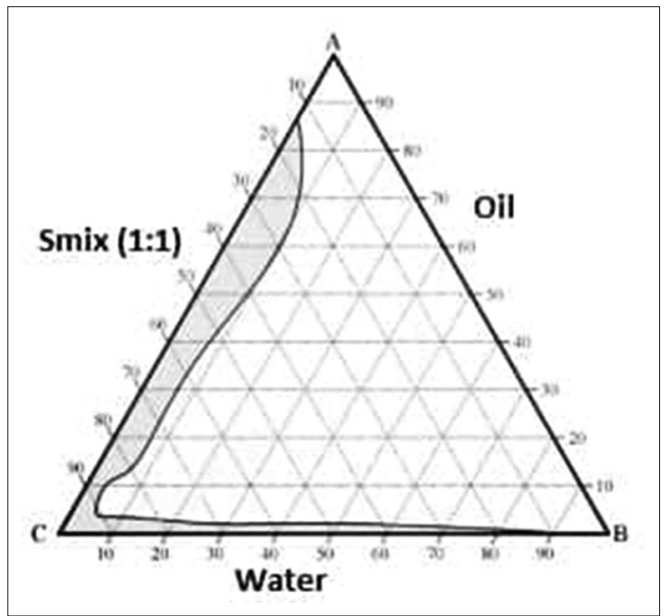

Fig. 1: Construction of pseudoternary phase diagram with Smix ratio 1:1

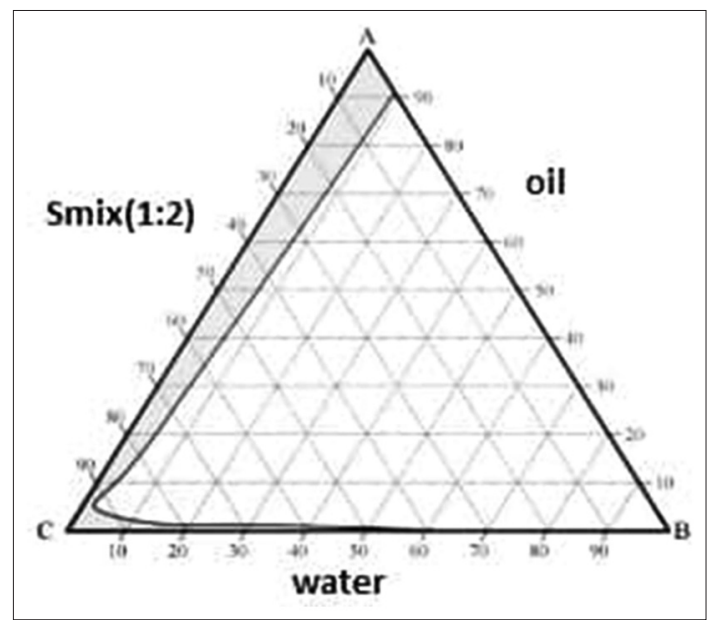

Fig. 2: Construction of pseudoternary phase diagram with Smix ratio 1:2

$(1: 1,1: 2$, and $1: 3)$. These ratios were chosen in increasing concentration of cosurfactant with respect to surfactant for a detailed study of phase diagram. For each phase diagram, oil and Smix at specific ratios were mixed thoroughly at different mass ratios from 1:1 to $1: 3$ in different glass vials. 10 different combinations of oil and Smix were made so that maximum ratios were covered for the study.

The ternary phase diagram for oil, Smix [18], and aqueous phase was developed using aqueous filtration method. To the oil and Smix mixture, aqueous phase is added slowly and titrated. Visual observations were made for emulsions. The physical state was marked on the pseudoternary phase diagram with one axis representing water, the

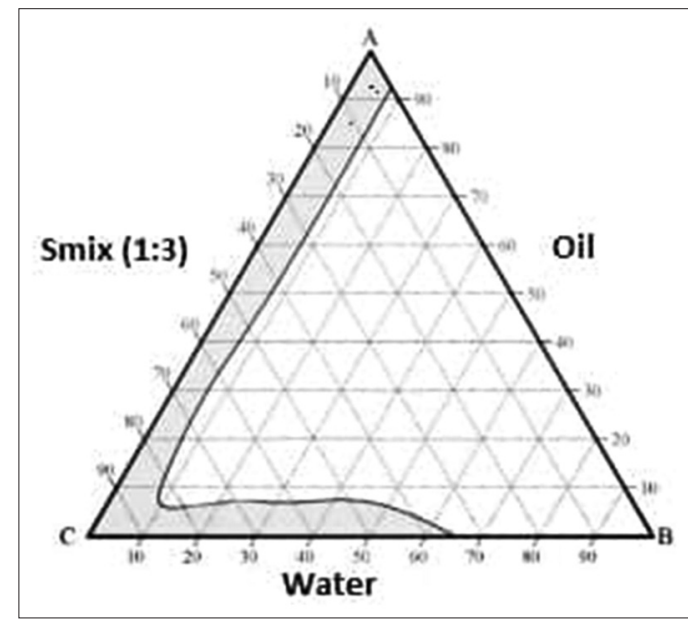

Fig. 3: Construction of pseudoternary phase diagram with Smix ratio 1:3

second one representing oil phase, and third representing a mixture of surfactant and cosurfactant at a fixed mass ratio.

\section{RESULTS AND DISCUSSION}

Solubility studies

Optimization of oil

Lipophilic drugs were preferably solubilized in oil-in-water $(0 / W)$ nanoemulsion where $\mathrm{W} / \mathrm{O}$ system seems to be better choice for hydrophilic drugs. The volume of the formulation should be minimized as much as possible to deliver the therapeutic dose. Solubility of the drug in the oil phase was an important criterion for the selection of oils. The surfactant and cosurfactant are contributing to drug solubilization.

The solubility of budesonide in different oils is shown in Table 1. The solubility of drug is found to be highest in polyoxyl 35 as compared to other oils. The castor oil was selected as the oil phase for the development of nanoemulsion formulation.

\section{Optimization of surfactants}

It is important to determine the surfactant concentration in the formulation. 0/W nanoemulsion dosage forms [19] for oral or parental use based on non-ionic surfactants are likely to offer in vivo stability. Another important criterion is the selection of cosurfactant to lower the necessary interfacial energy to form the nanoemulsion, consequently improving the solubility. In the present study, tween 80 , ethanol, PG, tween 20, tween 80, Transcutol, PEG 200, and PEG 400 were chosen for screening. Tween 80 and ethanol were selected as the surfactant and cosurfactant due to its high miscibility with oil phase.

\section{Preparation of pseudoternary phase diagram}

Pseudoternary phase diagram was constructed separately for each Smix ratio [20] so that $\mathrm{O} / \mathrm{W}$ nanoemulsion region could be identified 
and optimized. The relationship between the phase behavior of the surfactant mixture and other components is captured using phase diagram. In Fig. 1, the Smix ratio was 1:1 where the nanoemulsion area has been narrow when the surfactant ratio is high. In Fig. 2, the surfactant and cosurfactant were mixed in same ratio 1:2 where the maximum concentration of oil $85 \%$ has been solubilized and the nanoemulsion area increased. It may be due to further reduction of the interfacial tension, increasing the fluidity of the interface, thereby increasing the entropy of the system. In Fig. 3, the ratio was 1:3 where the cosurfactant increased and the nanoemulsion area has been decreased which states that high amount of cosurfactant mixture may not have the effect on interfacial tension. Hence, using a constructed phase diagram, the optimum ratios of the components for nanoemulsion which would remain stable and prevent drug precipitation over infinite dilution were selected as $85 \mu \mathrm{l}$.

\section{CONCLUSION}

Pseudoternary phase diagram for the solubility studies was constructed, and the components of different phases were optimized for further formulation of budesonide into nanoemulsion as anti-inflammatory agent.

\section{AUTHORS' CONTRIBUTIONS}

All the authors contributed equally.

\section{CONFLICTS OF INTEREST}

Authors have no conflicts of interest.

\section{REFERENCES}

1. Malothu N, Veldandi UK, Yellu NR, Yadala N, Devarakonda RK, Chaudhary A. Population pharmacokinetics of budosenide In Indian Chris's disease patient population. Asian J Pharm Clin Res 2010;3:3-24.

2. Maha HL, Sinaga KR, Fria M. Formulation and evaluation of miconazole nitrate nanoemulsion and cream. Asian J Pharma Clin Res 2018;11:319-21.

3. Chaudhari PM, Kuchekar MA, Laxmi M, Bhardwaj A, Mehta S, Mehta A. Development and evaluation of nanoemulsion as a carrier for topical delivery system by box-behnken design. Asian J Pharm Clin Res 2018;11:286-93.

4. Lawrence MJ, Rees GD. Microemulsion-based media as novel drug delivery systems. Adv Drug Deliv Rev 2000;45:89-121.

5. Tenjarla S. Microemulsions: An overview and pharmaceutical applications. Crit Rev Ther Drug Carrier Syst 1999;16:461-521.

6. Courrier H, Krafft MP, Nakamura S, Shibata O, Vandamme T. Waterin-fluorocarbon reverse emulsion as a pulmonary drug delivery system: Effect on the lung as modelled by a phospholipid monolayer. S T P
Pharma Prat 2003;13:22-6.

7. Patel N, Marlow M, Lawrence MJ. Formation of fluorinated nonionic surfactant microemulsions in hydrofluorocarbon 134a (HFC 134a). J Colloid Interface Sci 2003;258:345-53.

8. Patel N, Marlow M, Lawrence MJ. Fluorinated ionic surfactant microemulsions in hydrofluorocarbon 134a (HFC 134a). J Colloid Interface Sci 2003;258:354-62.

9. Sommerville ML, Hickey AJ. Aerosol generation by metered-dose inhalers containing dimethyl ether/propane inverse microemulsions. AAPS Pharm Sci Tech 2003;4:E58

10. Sommerville ML, Johnson CS Jr. Cain JB, Rypacek F, Hickey AJ. Lecithin microemulsions in dimethyl ether and propane for the generation of pharmaceutical aerosols containing polar solutes. Pharm Dev Technol 2002;7:273-88.

11. Hvizdos KM, Jarvis B. Budesonide inhalation suspension: A review of its use in infants, children and adults with inflammatory respiratory disorders. Drugs 2000;60:1141-78.

12. Ali HS, York P, Blagden N, Soltanpour S, Acree WE Jr., Jouyban A. Solubility of budesonide, hydrocortisone, and prednisolone in ethanol + water mixtures at 298.2 K. J Chem Eng Data 2010;55:578-82.

13. Ek A, Larsson K, Siljerud S, Palmberg L. Fluticasone and budesonide inhibit cytokine release in human lung epithelial cells and alveolar macrophages. Allergy 1999;54:691-9.

14. Meloche CA, Sharma V, Swedmark S, Andersson P, Falany CN. Sulfation of budesonide by human cytosolic sulfotransferase, dehydroepiandrosterone-sulfotransferase (DHEA-ST). Drug Metab Dispos 2002;30:582-5.

15. Piao HM, Cho HJ, Oh EC, Chung SJ, Shim CK, Kim DD. Budesonide microemulsions for enhancing solubility and dissolution rate. J Korea Pharm Sci 2009;39:417-22

16. Shimada T, Ueda M, Jinno H, Chiba N, Wada M, Watanabe J, et al. Development of targeted therapy with paclitaxel incorporated into EGF-conjugated nanoparticles. Anticancer Res 2009;29:1009-14.

17. Baboota S, Shakeel F, Ahuja A, Ali J, Shafiq S. Design, development and evaluation of novel nanoemulsion formulations for transdermal potential of celecoxib. Acta Pharm 2007;57:315-32.

18. Shafiq S, Faiyaz S, Sushma T, Farhan JA, Khar RH, Ali M. Design and development of ramipril nanoemulsion formulation: In vitro and in vivo assessment. J Biomed Nanotechnol 2007;3:28-44.

19. Shafiq S, Faiyaz S, Sushma T, Farhan JA, Khar RK, Ali M. Development and bioavailability assessment of ramipril nanoemulsion formulation. Eur J Pharm Biopharm 2007;66:227-43.

20. Jain J, Fernandes C, Patravale V. Formulation development of parenteral phospholipid-based microemulsion of etoposide. AAPS PharmSciTech 2010;11:826-31.

21. Rowe RC, Sheskey PJ, Weller PJ, editor. Handbook of Pharmaceutical Excipients. $4^{\text {th }}$ ed. Washington: Pharmaceutical Press, London/ American Pharmaceutical Association; 2003.

22. Shafiq-un-Nabi S, Shakeel F, Talegaonkar S, Ali J, Baboota S, Ahuja A, et al. Formulation development and optimization using nanoemulsion technique: A technical note. AAPS PharmSciTech 2007;8:28. 